\title{
Crónica de Derecho Canónico 2016
}

Joaquín SEDANO

Profesor Adjunto de Historia del Derecho Canónico Universidad de Navarra. Facultad de Derecho Canónico orcid 0000-0002-7116-987X

jsedano@unav.es

Resumen: Se da noticia de los principales documentos y actos jurídicos dados en el año 2016 por el romano pontífice y los distintos dicasterios de la curia romana, así como de los acuerdos internacionales suscritos por la Santa Sede. También se hace referencia a la actividad canónica en el ámbito de la Conferencia Episcopal Española.

Palabras clave: Crónica, Derecho canónico, Curia romana, Acuerdos internacionales de la Santa Sede, Conferencia Episcopal Española.
Abstract: The Chronicle reports the main documents and legal acts issued in 2016 by the papa and the various dicasteries of the roman curia, as well as the international agreements signed by the Holy See. Canonical activity undertaken by the Spanish Episcopal Conference is also covered.

Keywords: Chronicle, Canon Law, Roman Curia, International Agreements of the Holy See, Spanish Episcopal Conference.

SUMARIO: 1. Romano pontífice. 1.1. Escritos y documentos. 1.2. Erección y reorganización de circunscripciones eclesiásticas. 1.3. Otros actos pontificios. 2. Curia romana. 2.1. Congregaciones. 2.1.1. Congregación para el Culto Divino y la Disciplina de los Sacramentos. 2.1.2. Congregación para las Causas de los Santos. 2.1.3. Congregación para la Educación Católica. 2.1.4. Congregación para los Institutos de Vida Consagrada Apostólica. 2.1.5. Congregación para la Doctrina de la Fe. 2.1.6. Congregación para los IVC y SVA. 2.2. Consejos Pontificios. 2.2.1. Consejo Pontificio para los Textos Legislativos. 2.3. Tribunales. 2.3.1. Tribunal Supremo de la Signatura Apostólica. 2.4. Otros dicasterios. 2.4.1. Secretaría para la Comunicación. 2.4.2. Academia Pontificia para la Vida. 2.4.3. Nuevo dicasterio para los Laicos, la Familia y la Vida. 2.4.4. Nuevo dicasterio para el Servicio del Desarrollo Integral Humano. 3. Relaciones internacionales de la Santa Sede. 4. Conferencia Episcopal Española. 
$\mathrm{D}$ esde el punto de vista organizativo, el año 2016 se caracteriza por nuevas e importantes disposiciones del romano pontífice en relación con dicasterios de la curia romana. En esta ocasión se han creado dos nuevos dicasterios: el dicasterio para los Laicos, la Familia y la Vida, que absorbe a los antiguos consejos pontificios para los Laicos y para la Familia; y el dicasterio para el Servicio del Desarrollo Integral Humano, que absorbe y unifica a los antiguos consejos pontificios Justicia y Paz, «Cor unum», Pastoral de los Emigrantes e Itinerantes, y Pastoral de la Salud. Estos cambios han conllevado la derogación de los correspondientes artículos de la constitución apostólica Pastor bonus.

Legislativamente, la novedad más importante ha sido la modificación, mediante la carta apostólica De concordia inter Codices, del texto de una serie de cánones del CIC, para la mejor armonía con el CCEO en la atención pastoral de fieles de rito oriental.

Pero además, otros actos pontificios han afectado a diversos cánones. Concretamente, el art. 1 de la constitución apostólica Vultum tuum quaerere (sobre la vida contemplativa femenina) establece la abrogación de los cánones que resulten directamente contrarios a cualquier artículo de ese documento. Además, mediante rescriptum ex audientia el papa precisó que la consulta a la Santa Sede por parte del obispo diocesano para la erección de institutos de vida consagrada (cfr. c. 579) se trata de un requisito ad validitatem.

Por otra parte, la instrucción Ad resurgendum cum Christo (sobre la sepultura de los difuntos y la conservación de las cenizas en caso de cremación), publicada por la Congregación para la Doctrina de la Fe, precisa algunas indicaciones sobre la conservación de las cenizas que no están recogidas en el c. 1176 $\$ 3$. Además el Consejo Pontifico para los Textos Legislativos ha publicado una respuesta auténtica sobre el c. $1041, \mathrm{nn} .4^{\circ}-5^{\circ}$, en relación con algunas irregularidades para recibir el orden sagrado.

Otro acontecimiento destacable es la publicación de la nueva Ratio Fundamentalis Institutionis Sacerdotalis por parte de la Congregación para la Educación Católica. 


\section{CRÓNICA DE DERECHO CANÓNICO}

\section{ROMANO PONTÍFICE}

\subsection{Escritos y documentos (Discurso a la Rota Romana; ex. ap. «Amoris}

laetitia»; m.p. «Como una madre amorosa»; const. ap. «Vultum tuum quaerere»; m.p. «De concordia inter Codices»; carta ap. «Misericordia et misera»)

- El 22 de enero, en el discurso con motivo de la inauguración del año judicial, el papa Francisco denominó a la Rota Romana como el «Tribunal de la verdad del vínculo sagrado», puesto que «tanto al juzgar como al contribuir a la formación permanente, asiste y promueve el opus veritatis». Al mismo tiempo recordó que «la calidad de la fe no es una condición esencial del consentimiento matrimonial», ya que «las deficiencias de formación en la fe y también el error relativo a la unidad, la indisolubilidad y la dignidad sacramental del matrimonio vician el consentimiento matrimonial solamente si determinan la voluntad».

- Con fecha de 19 de marzo apareció publicada la exhortación apostólica postsinodal Amoris laetitia, sobre el amor en la familia. El documento del papa ha tenido muy en cuenta los sínodos de los años 2014 y 2015, dedicados a la familia. La exhortación no presenta precisiones canónicas, como el propio papa reconoció en una entrevista concedida al diario francés «La Croix», sino una reflexión serena sobre la belleza del amor, la preparación al matrimonio y la educación de los hijos, entre otros aspectos. El pontífice presta una especial importancia también a la atención pastoral de los fieles que se encuentran en una situación matrimonial irregular, de modo que se les haga sentir que son parte de la Iglesia «evitando todo lenguaje y actitud que las haga sentir discriminadas, y promoviendo su participación en la vida de la comunidad. Para la comunidad cristiana, hacerse cargo de ellos no implica un debilitamiento de su fe y de su testimonio acerca de la indisolubilidad matrimonial, es más, en ese cuidado expresa precisamente su caridad» (n. 243).

- Con fecha 4 de junio, el santo padre publicó el m.p. Come una madre amorevole, donde incide en la posibilidad de la remoción de obispos y a ellos equiparables según los cánones 386 CIC y 313 CCEO -entre los que se encuentran en este caso también los superiores mayores de institutos religiosos y de sociedades de vida apostólica de derecho pontificio- si se demuestra que han sido negligentes en la protección de indefensos y vulnerables o en el ejercicio de su oficio pastoral. El documento entró en vigor el 5 de septiembre. 
- Con fecha de 29 de junio el santo padre firmó la const. ap. Vultum tuum quaerere, sobre la vida contemplativa femenina. El documento tiene en cuenta las enseñanzas del Concilio Vaticano II a la luz de las nuevas condiciones socioculturales. El pontífice invita a reflexionar sobre doce aspectos de la vida consagrada. Desde el punto de vista jurídico destacan la legítima autonomía de los monasterios, que no debe significar sin embargo «independencia o aislamiento, en particular de los demás monasterios de la misma Orden o de la familia carismática» (n. 28); el reforzamiento de las federaciones; y la legítima pluralidad de los modos de observar la clausura en una misma Orden, que deben ser considerados «como una riqueza y no como un impedimento para la comunión» (n. 31).

La constitución finaliza con una serie de artículos dispositivos. Concretamente, en el art. 1 se indica que quedan abrogados los cánones del CIC que, en parte, resulten directamente contrarios a cualquier artículo de la presente constitución; y, más en particular, los artículos dispositivo-normativos de los siguientes documentos: los Statuta generalia monialium de la const. ap. Sponsa Christi de Pío XII de 1950; la instr. Inter praeclara, de la Sagrada Congregación para los Religiosos; y la instr. Verbi Sponsa, de la Congregación para los IVC y SVA, de 13 de mayo de 1999.

$\mathrm{El}$ art. 14 ordena que la Congregación para los IVC y SVA promulgue una nueva instrucción sobre las materias indicadas en el n. 12 y que las adaptaciones de las diversas constituciones y reglas a estas disposiciones deben someterse a la aprobación de la Santa Sede.

- Sobre la carta ap. De concordia inter Codices, vid. «Consejo Pontifico para los Textos Legislativos» (apdo. 2.3).

- Al concluir el Jubileo de la Misericordia el santo padre firmó, con fecha de 20 de noviembre, la carta apostólica Misericordia et misera. Desde el punto de vista disciplinar, la carta extiende en el tiempo algunas de las disposiciones extraordinarias introducidas durante el Jubileo.

Concretamente, en el n. 12 del documento se concede de modo general a todos los sacerdotes, en razón de su ministerio, la facultad de absolver de la censura de excomunión en la que se incurre por el delito de aborto. Además, extiende hasta nueva disposición la facultad concedida a los sacerdotes de la Fraternidad San Pío X de confesar válida y lícitamente a los fieles que acuden a sus iglesias. Esto último como un claro gesto para facilitar el regreso a la plena comunión de esta institución. 
Por otra parte, el papa prolonga el ministerio de los «Misioneros de la Misericordia», haciéndolo depender del Consejo Pontifico para la Promoción de la Nueva Evangelización (n. 9).

\subsection{Erección y reorganización de circunscripciones eclesiásticas}

- El 20 de enero, por decreto de la Congregación para los Obispos, el entero territorio municipal de São José da Safira en Brasil quedó desmembrado de la diócesis de Guanhães y pasó a la diócesis de Governador Valadares ${ }^{1}$.

- El 25 de enero el papa Francisco erigió la diócesis de San Francisco de Asís de Jutiapa (población 458.321, 389.573 católicos, 24 sacerdotes, 82 religiosos) en Guatemala, con territorio desmembrado de la diócesis de Jalapa y haciéndola sufragánea de la archidiócesis de Santiago de Guatemala².

El mismo día trasladó a la Congregación para los Obispos las competencias sobre las siguientes circunscripciones de Canadá septentrional, hasta entonces dependientes de la Congregación para la Evangelización de los Pueblos: Keewatin-Le, Churchill-Hudson Bay, Moosonee, Grouard-McLennan, Mckenzie-Fort Smith y Whitehorse.

- El 15 de marzo erigió la diócesis de Kumba (población 562.988, 205.491 católicos, 41 sacerdotes, 44 religiosas) en Camerún, con territorio desmembrado de la diócesis de Buéa, haciéndola sufragánea de la sede metropolitana de Bamenda.

- El 11 de abril erigió la nueva diócesis de Rayagada (población 5.407.894, 50.542 católicos, 49 sacerdotes, 15 religiosos, 71 religiosas) en India, con territorio desmembrado de la diócesis de Berhampur, haciéndola sufragánea de la sede metropolitana de Cuttack-Bhubaneswar.

- El 20 de julio erigió la diócesis de Votuporanga (población 230.000, 172.500 católicos, 42 sacerdotes, 25 religiosos, 15 religiosas) en Brasil, con territorio desmembrado de las diócesis de São José do Rio Preto y de Jales, haciéndola sufragánea de la archidiócesis de Ribeirão Preto.

En relación con las Iglesias orientales católicas:

- El 4 de enero erigió la eparquía de St. Mary Queen of Peace de Estados Unidos de América y Canadá de los Siro-Malankareses.

\footnotetext{
${ }^{1}$ AAS 108 (2016) 193.

2 Ibid., 102-103.
} 
- El 7 de enero erigió el exarcado apostólico para los fieles siro-católicos residentes en Canadá, con sede en Montreal, con territorio desmembrado de la eparquía Our Lady of Deliverance of Newark de los Siro-Católicos en Estados Unidos de América.

- El 20 de enero erigió el exarcado apostólico para los fieles maronitas residentes en Colombia con sede en Bogotá.

- El 9 de junio se hizo pública la erección del Ordinariato para los fieles católicos orientales residentes en España y el nombramiento como ordinario de mons. Carlos Osoro Sierra, arzobispo de Madrid. Hasta entonces los católicos de rito oriental en España dependían del obispo del lugar donde residían ${ }^{3}$.

- El 28 de julio erigió la eparquía de Gran Bretaña de los Siro-Malabares, con sede en Preston.

1.3. Otros actos pontificios (Modificación rúbricas rito del lavatorio de los pies; Normas administración de bienes en causas de beatificación y canonización; necesidad consulta para erección de IVC; creación del dicasterio para los Laicos, la Familia y la Vida; creación del dicasterio para el Servicio del Desarrollo Integral Humano; m.p. «I beni temporali»)

- Sobre la modificación de las rúbricas del rito del lavatorio de los pies en la liturgia del Jueves Santo vid. «Congregación para el Culto Divino y la Disciplina de los Sacramentos» (apdo. 2.2.1).

- Normas sobre la administración de los bienes de las Causas de beatificación y canonización: vid. «Congregación para las Causas de los Santos» (apdo. 2.2.2).

- Mediante rescriptum ex audientia fechado el 20 de mayo, el santo padre precisó que la consulta previa del obispo diocesano a la Santa Sede para la erección de institutos de vida consagrada en el propio territorio (cfr. c. 579) a partir del 1 de junio de 2016 pasaba a considerarse como un requisito ad validitatem. Un documento firmado por el cardenal Secretario de Estado explica

3 Cfr. BOCEE 97 (2016) 116. Recuérdese que en la LXXXI Asamblea Plenaria de la CEE (17-21 de noviembre de 2003) se aprobó el documento «Orientaciones para la atención pastoral de los católicos orientales en España». Vid. el documento y el comentario correspondiente, A. KAPTIJN, Ordinariato Apostólico para la atención de los orientales en España, Ius Canonicum 56 (2016) 771-781. 
que el papa tomó la decisión siguiendo las sugerencias del Consejo Pontificio para los Textos Legislativos, para evitar que se erijan nuevos institutos diocesanos sin el suficiente discernimiento que verifique la originalidad del carisma y las posibilidades reales de desarrollo.

- Sobre la creación del nuevo dicasterio para los Laicos, la Familia y la Vida vid. «Nuevo dicasterio para los Laicos, la Familia y la Vida» (apdo. 2.5.3).

- Sobre la creación del dicasterio para el Servicio del Desarrollo Integral Humano vid. «Nuevo dicasterio para el Servicio del Desarrollo Integral Humano» (apdo. 2.5.4).

- Mediante carta ap. de 4 de julio el santo padre dictó una serie de normas para la correcta interpretación y aplicación de la carta ap. Fidelis dispensator et prudens, de 24 de febrero de 2014. De este modo se delimitan mejor los respectivos ámbitos de actividad de la Secretaría para la Economía y la Administración del Patrimonio de la Sede Apostólica. También se reafirma la directiva fundamental de separar netamente la gestión directa del patrimonio (correspondiente a la Administración del Patrimonio) del control y vigilancia sobre dicha actividad (función de la Secretaría para la Economía) $)^{4}$.

\section{CURIA ROMANA}

\subsection{Congregaciones}

\subsubsection{Congregación para el Culto Divino y la Disciplina de los Sacramentos} (Modificación rúbricas rito del lavatorio de los pies; sobre el culto con motivo de peregrinaje de reliquias; celebración de santa María Magdalena como fiesta)

- El 21 de enero se dio a conocer una carta del santo padre ${ }^{5}$, de 20 de diciembre de 2014, dirigida al cardenal Robert Sarah en la que disponía que se modificasen las rúbricas de modo que para el lavatorio de los pies de la liturgia del Jueves Santo se pudiese escoger entre todo el Pueblo de Dios, y no solamente varones. Para hacer efectiva la indicación pontificia, esta Congregación

\footnotetext{
${ }^{4}$ Vid. el motu propio y el comentario correspondiente, D. ZALbidea GonZález, Delimitación de competencias de la Secretaría de asuntos económicos en relación con la Administración del Patrimonio de la Sede Apostólica, Ius Canonicum 56 (2016) 787-795.

5 AAS $108(2016) 107$.
} 
dio un decreto, con fecha de 6 de enero de $2016^{6}$, por el que se modifican las rúbricas del Misal Romano (allí donde dice «Los hombres elegidos son acompañados por los ministros» debe variar como sigue: «Los elegidos entre el Pueblo de Dios son acompañados por los ministros») y del Ceremonial de los Obispos, nn. 229b y 301 (allí donde dice «sillas para los varones designados» deberá decir «las sillas para los designados»).

- Con fecha de 27 de enero el prefecto de esta congregación firmó una «Notificación sobre la concesión de culto con motivo del peregrinaje de reliquias de beatos» (Prot. N. 717/15). El documento recuerda algunos criterios generales que deben ser tenidos en cuenta en estas ocasiones: consentimiento de los obispos diocesanos interesados, lugar donde se puede celebrar el culto en honor del beato, modalidades de ceremonias litúrgicas y otras expresiones de piedad y devoción.

- Por expreso deseo del papa Francisco, esta congregación publicó el 3 de junio un decreto (Prot. N. 257/16) por el que la memoria obligatoria de santa María Magdalena pasa a tener la categoría de fiesta en el Calendario Romano General.

\subsubsection{Congregación para las Causas de los Santos (Normas sobre la} administración de los bienes de las Causas de beatificación y canonización; nuevo Reglamento de la Consulta Médica)

- El 4 de marzo, por Rescriptum ex audientia Sanctissimi, el santo padre aprobó las «Normas sobre la administración de los bienes de las Causas de beatificación y de canonización», abrogando las precedentes aprobadas por san Juan Pablo II, el 20 de agosto de 1983.

El documento que contiene las nuevas normas, firmado por el card. Angelo Amato y Mons. Marcello Bartolucci, prefecto y secretario de esta congregación, consta de 23 números. El objetivo principal de la reforma es facilitar la transparencia y la funcionalidad de la gestión de los bienes, donaciones y gastos realizados durante el proceso. Se introduce la figura del administrador, que es nombrado por el promotor de la causa con el consentimiento del respectivo obispo o eparca. $\mathrm{Al}$ administrador le compete toda la gestión económica que realizaba antiguamente el promotor. Debe llevar una

\footnotetext{
${ }^{6}$ Ibid., 192.
} 
contabilidad actualizada, presentar anualmente el balance y velar para que la administración del fondo respete escrupulosamente la voluntad de los oferentes.

Las normas han sido aprobadas ad experimentum por un tiempo de tres años desde su entrada en vigor.

- El 24 de agosto, el cardenal Secretario de Estado aprobó, de mandato Summi Pontificis, el nuevo «Reglamento de la Consulta Médica para los procesos de beatificación y canonización». La promulgación de la const. ap. Divinus perfectionis Magister (25 de enero de 1983) y la experiencia de los últimos años de esta congregación han aconsejado la reforma del anterior Reglamento, aprobado por Pablo VI el 23 de abril de 1976. El nuevo Reglamento, fechado el 23 de septiembre, consta de 20 artículos y lleva la firma del cardenal prefecto de la congregación.

\subsubsection{Congregación para la Educación Católica (Nueva «Ratio Fundamentalis Institutionis Sacerdotalis»)}

Con fecha de 8 de diciembre se publicó la nueva Ratio Fundamentalis Institutionis Sacerdotalis, aprobada por el romano pontífice. El documento, que regula el plan de formación de los sacerdotes desde los años del seminario, consta de 210 números. Entre las novedades en relación con la anterior $R a$ tio, destacan la obligatoriedad de la etapa propedéutica (nn. 59-60), por un periodo entre uno y dos años; la advertencia de que el obispo no debe publicar la fecha de ordenación diaconal antes de que el candidato haya aprobado todos los exámenes del currículum de los estudios filosóficos-teológicos (n. 206); y la mayor incidencia en la etapa pastoral previa a la ordenación presbiteral (nn. 74-79).

El ámbito de aplicación de la Ratio es el de aquellos países de competencia de la Congregación para el Clero. Cada conferencia episcopal debe elaborar la propia Ratio nationalis, que deberá ser aprobada por la Congregación para la Educación Católica (nn. 3-5).

\subsubsection{Congregación para los Institutos de Vida Consagrada y Sociedades de Vida Apostólica (Necesidad consulta para erección de IVC)}

Sobre la obligatoriedad de la consulta previa del obispo diocesano a la Santa Sede para la erección de un instituto de vida consagrada vid. información en «Otros actos pontificios» (apdo. 1.3). 


\subsubsection{Congregación para la Doctrina de la Fe (Excomunión; carta «Iuvenescit Ecclesia»; instr. «Ad resurgendum cum Christo»)}

- El domingo 5 de junio se leyó en la misa de las parroquias de la diócesis italiana de Sora-Casino-Aquino-Pontecorvo un decreto de esta congregación que declaraba que incurrían en excomunión latae sententiae los fieles que conscientemente se adhiriesen a la organización cismática «Niño Jesús de Gallinaro», por la difusión de doctrinas falsamente religiosas y enseñanzas bíblicas extrañas a la verdad de los textos sagrados. Esta organización pseudorreligiosa gira en torno al culto a la difunta vidente Giuseppina Norcia ${ }^{7}$.

- Con fecha de 15 de mayo se publicó la carta Iuvenescit Ecclesia, sobre la relación entre los dones jerárquicos y carismáticos en la Iglesia. Entre otros aspectos, el documento enumera ocho criterios para el discernimiento de los dones carismáticos pertenecientes a grupos eclesiales (n. 18). Al mismo tiempo, se alude al necesario respeto por parte de la jerarquía de los carismas de esos grupos «evitando forzamientos jurídicos que mortifiquen la novedad de la cual la experiencia específica es portadora» $y$, correlativamente, al respeto del régimen eclesial fundamental por parte de los grupos carismáticos de modo que se evite «que la realidad carismática se conciba paralelamente a la vida de la Iglesia y no en una referencia ordenada a los dones jerárquicos» (n. 23). Este mismo n. 23 hace referencia a las diversas formas jurídicas que puede adoptar el reconocimiento de estas realidades. El papa Francisco aprobó esta carta en la audiencia concedida el 14 de marzo al prefecto de esta congregación.

- El 15 de agosto el card. Müller firmó la instrucción Ad resurgendum cum Christo, sobre la sepultura de los difuntos y la conservación de las cenizas en caso de cremación. El papa había aprobado este documento el 18 de marzo.

La instrucción pretende reafirmar la dignidad del cuerpo humano, el respeto hacia los fieles difuntos y la necesidad de favorecer el recuerdo y la oración por ellos. Frente a las nuevas ideas en desacuerdo con la fe de la Iglesia que se propagan en la cultura actual, el documento recuerda las razones doctrinales y pastorales que aconsejan la preferencia de la sepultura de los cuerpos al mismo tiempo que dicta algunas normas relativas a la conservación de las cenizas en caso de cremación.

En este sentido la instrucción reafirma que la «Iglesia recomienda insistentemente que los cuerpos de los difuntos sean sepultados en los cementerios

${ }^{7}$ Vid. servicio informativo de la agencia de noticias Zenit de 6 de junio. 
u otros lugares sagrados» (n. 3). Ante la ausencia de indicaciones específicas del c. $1176 \$ 3$, el art. 5 de la instrucción establece que «si por razones legítimas se opta por la cremación del cadáver, las cenizas del difunto, por regla general, deben mantenerse en un lugar sagrado, es decir, en el cementerio o, si es el caso, en una iglesia o en un área especialmente dedicada a tal fin por la autoridad eclesiástica competente». Además recuerda que no se permite la conservación de las cenizas en el hogar, salvo en casos de «graves y excepcionales circunstancias» y con el permiso del ordinario del lugar de acuerdo con la conferencia episcopal o el sínodo de los obispos de las Iglesias orientales (n. 6). Junto a los supuestos indicados en el c. $1184 \$ 1$, por los que se han de negar las exequias eclesiásticas, la instrucción añade el supuesto de que «el difunto hubiera dispuesto la cremación y la dispersión de sus cenizas en la naturaleza por razones contrarias a la fe cristiana» (n. 8) ${ }^{8}$.

\subsubsection{Congregación para los IVC y SVA (Const. ap. «Vultum tuum quaerere»)}

Sobre la const. ap. Vultum tuum quaerere vid. «Escritos y documentos» (apdo. 1.1).

\subsection{Consejos pontificios}

\subsubsection{Consejo Pontifico para los Textos Legislativos (M.p. «De concordia} inter Codices»; respuesta auténtica c. 1041, nn. $4^{\circ}-5^{\circ}$ )

- Con fecha de 31 de mayo el romano pontífice firmó la carta ap. De concordia inter Codices por la que se modifican una serie de cánones del CIC. En el contexto actual de gran movilidad humana se ha querido limar algunas diferencias disciplinares entre el CIC y el CCEO que repercutían negativamente en la praxis pastoral. Los cánones del CIC afectados son los siguientes: 111$112,535 \$ 2,868,1108-1109,1111 \$ 1,1112 \$ 1,1116$ y $1127 \$ 1$.

Los principales cambios afectan, en primer lugar, al bautismo, que en el caso de que sólo uno de los cónyuges sea católico, el niño será adscrito a la

\footnotetext{
${ }^{8}$ Para mayor información vid. revista Ecclesia 3858 (2016) 1760-1761.

9 El motu proprio, junto con los cambios introducidos en el CIC, puede descargarse en versión latina-italiana en el siguiente link: http://www.unav.edu/documents/192342/11421211/Addenda_CDC_2016sinmarcas/58573bba-de82-4964-89fe-917f86ad4c1f.
} 
Iglesia a la que pertenezca el progenitor católico. En cuanto al matrimonio, se precisa que sólo el sacerdote -y no el diácono- asiste válidamente el matrimonio donde al menos uno de los contrayentes sea oriental (católico o no). Además, el ordinario del lugar puede conferir a cualquier sacerdote la facultad de bendecir el matrimonio de files orientales no católicos que lo pidan espontáneamente y no obste ningún impedimento o prohibición. En relación con el cambio a otra Iglesia sui iuris, éste tiene valor desde el momento de la declaración ante el ordinario, el propio párroco o el sacerdote delegado.

- Con fecha de 15 de septiembre se publicó una respuesta auténtica al c. $1041, \mathrm{nn} .4^{\circ}-5^{\circ}$ del CIC, sobre algunas irregularidades para recibir el orden sagrado. Concretamente, el dubium planteaba si incurren en irregularidad los no católicos por los actos indicados en los $\mathrm{nn} .4^{\circ}$ y $5^{\circ}$, esto es: la comisión de homicidio voluntario o aborto, así como la cooperación positiva en los mismos; y la mutilación dolosa y grave de sí mismo o de otra persona o el intento de suicidio. La respuesta es afirmativa. El papa, en audiencia concedida al prefecto de este consejo pontificio el 31 de mayo, confirmó y ordenó que se publicara esta respuesta.

\subsection{Tribunales}

\subsubsection{Tribunal Supremo de la Signatura Apostólica (Carta circular «Inter munera»)}

El prefecto de este tribunal envió una carta circular, fechada el 30 de julio, por la que daba a conocer la reforma de las normas y el esquema de la relación anual sobre el estado y actividad de cada tribunal. Esta revisión era necesaria tras casi cincuenta años de vigencia de las anteriores normas y con motivo de los numerosos cambios introducidos, especialmente la reforma de los cánones de ambos códigos en relación con las causas para la declaración de la nulidad del matrimonio tras la publicación de las cartas ap. Mitis Iudex Dominus Iesus y Mitis et misericors Iesus. El modelo de los informes anuales puede descargarse en el sitio web de este tribunal.

\subsection{Otros dicasterios}

\subsubsection{Secretaría para la Comunicación (Estatutos)}

Con fecha de 6 de septiembre el papa Francisco firmó los estatutos de la Secretaría para la Comunicación, nuevo órgano creado el 27 de junio de 
$2015^{10}$. El art. $1 \$ 2$ especifica que esta Secretaría «aúna todas las realidades de la Santa Sede que se ocupan de la comunicación, para que todo el sistema responda de manera coherente a las necesidades de la misión evangelizadora de la Iglesia». Los estatutos entraron en vigor el 1 de octubre.

\subsubsection{Academia Pontificia para la Vida (Estatutos)}

El 18 de octubre el papa Francisco publicó los estatutos de la Academia Pontificia para la Vida por un tiempo de cinco años y mandó que entraran en vigor el 1 de enero de 2017. Al mismo tiempo remitió al cardenal Secretario de Estado la aprobación del reglamento propio de este dicasterio.

\subsubsection{Nuevo dicasterio para los Laicos, la Familia y la Vida (Erección) ${ }^{11}$}

Mediante la carta ap. Sedula Mater, de 15 de agosto, el papa Francisco creó el nuevo dicasterio «para los Laicos, la Familia y la Vida», que absorbió a los consejos pontificios para los Laicos y para la Familia. El 1 de septiembre cesaron en sus funciones estos dicasterios y, en consecuencia, quedaron derogados los arts. 131-134 y 139-141 de la const. ap. Pastor bonus. El 4 de junio el papa aprobó ad experimentum los estatutos del nuevo dicasterio. Nombró además como prefecto a mons. Kevin Joseph Farrel, obispo de Dallas.

\subsubsection{Nuevo dicasterio para el Servicio del Desarrollo Integral Humano (Erección)}

Mediante un motu proprio con fecha de 17 de agosto, el papa Francisco creó un nuevo dicasterio que absorbe y unifica a cuatro consejos pontificios: Justicia y Paz, «Cor unum», Pastoral de los Emigrantes e Itinerantes, y Pastoral de la Salud. El nuevo dicasterio comenzó su actividad el 1 de enero de 2017, el mismo momento en que cesaron los antiguos dicasterios. Por consiguiente quedaron derogados los arts. 142-153 de la const. ap. Pastor bonus. Este dicasterio es competente, de modo particular, para las cuestiones refe-

${ }^{10}$ Más información sobre este asunto en Crónica de derecho canónico 2015, Ius Canonicum 56 (2016) 395.

${ }^{11}$ No ha sido todavía definido el estatuto de estos dos nuevos dicasterios, si quedarán como consejos pontificios, congregaciones u otra modalidad. Sobre las reformas de la curia romana vid. A. VIANA, Elementos de la futura reforma de la curia romana prevista por el papa Francisco, ibid., 271-299. 
rentes a las migraciones, los necesitados, los enfermos y los excluidos, los marginados y las víctimas de los conflictos armados y de las catástrofes naturales, los encarcelados, los desempleados y las víctimas de cualquier forma de esclavitud y de tortura.

Los estatutos, aprobados ad experimentum, llevan también fecha de 17 de agosto. En ellos se indica que una sección especial del dicasterio, ocupada específicamente de lo relativo a los refugiados y emigrantes, queda ad tempus bajo la guía directa del sumo pontífice (art. $1 \$ 4$ ). El dicasterio consta de tres comisiones: para la caridad, para la ecología y para los profesionales sanitarios (art. $4 \$ 5$ ). Caritas internationalis pasa a depender de este dicasterio (art. 4 $\$ 6)$.

El card. Peter Turkson, antiguo presidente del Consejo Pontificio Justicia y Paz, ha sido nombrado prefecto del nuevo dicasterio.

\section{Relaciones internacionales de la Santa Sede}

(Entrada en vigor acuerdo con Estado Palestino; relaciones con China; acuerdo con Timor Oriental; acuerdo con el Congo; acuerdo con República Centroafricana; acuerdo con Emiratos Árabes Unidos; acuerdo fiscal con Italia; acuerdo con Benin; reunión grupo de trabajo Santa Sede-Vietnam; acuerdo con Francia sobre Trinità dei Monti; relaciones con Mauritania)

- El 2 de enero entró en vigor el acuerdo entre la Santa Sede y el Estado de Palestina, firmado el 26 de junio de $2015^{12}$. El acuerdo, que consta de un preámbulo y de 32 artículos regula aspectos del funcionamiento de la Iglesia católica en Palestina, como el régimen fiscal de sus propiedades, la exención del servicio militar para su personal y la cuestión de los santos lugares ${ }^{13}$.

- A pesar de los intentos de la Santa Sede de iniciar una etapa más pacífica en las relaciones con la República Popular China, lo cierto es que diversas actuaciones de las autoridades chinas han provocado nuevas tensiones. El 8 de septiembre la Oficina del Consejo de Estado para los asuntos legislativos difundió un borrador sobre los reglamentos relativos a las actividades religiosas, que deberá sustituir los vigentes reglamentos del año 2004. A pesar de que

\footnotetext{
AAS 108 (2016) 168-185.

${ }^{13}$ Vid. más información sobre este acuerdo en Crónica de derecho canónico 2015, Ius Canonicum 56 (2016) 413-414.
} 
el documento reconoce la libertad religiosa de los ciudadanos, las restricciones a dicha libertad son severas y se prescribe que, para ejercer el ministerio, todo ministro de culto deberá registrarse en el Ministerio de Asuntos Religiosos. Este registro está ya en marcha y, aunque no se dice nada en los reglamentos, la inscripción se realiza en la práctica a través de la Asociación $\mathrm{Pa}$ triótica China.

Entre el 26 y el 30 de noviembre se celebró en Pekín la novena Asamblea de los Representantes Católicos de China, controlada por el régimen comunista y organizada por la Asociación Patriótica China. En esta ocasión, para rebajar la tensión, el Vaticano emitió una nota en la que no prohibía a los obispos fieles a Roma su participación en ella, pero dejaba constar su dolor por las últimas dos ordenaciones episcopales conferidas sin mandato pontificio.

- El 3 de marzo, mediante el intercambio de los instrumentos de ratificación, se ratificó el acuerdo entre la Santa Sede y la República Democrática de Timor Oriental firmado en Díli el 4 de agosto de 2015. El acuerdo otorga la personalidad jurídica a la Iglesia y sus instituciones y garantiza la libertad para el desarrollo de su misión.

- El 20 de mayo se firmó en el Palacio Apostólico Vaticano un acuerdo marco entre la Santa Sede y la República Democrática del Congo. El acuerdo reconoce la personalidad jurídica de la Iglesia y la libertad para desarrollar su actividad apostólica y regular las materias de su competencia. Entre otros aspectos se regulan las instituciones católicas de educación, la enseñanza de la religión en las escuelas, las actividades de asistencia y caridad de la Iglesia, la atención pastoral de los miembros de las fuerzas armadas y en los establecimientos penitenciarios y hospitalarios, el régimen patrimonial y fiscal, y la obtención de visados de entrada y de permisos de residencia para el personal religioso. El acuerdo entrará en vigor cuando se intercambien los instrumentos de ratificación.

- El 6 de septiembre, en el Palais de la Renaissance de Bangui, sede de la Presidencia de la República Centroafricana, y en presencia del Jefe del Estado, Faustin Archange Touadéra, se firmó el Acuerdo Marco entre la Santa Sede y la República Centroafricana sobre asuntos de interés común. El acuerdo entrará en vigor con el intercambio de los instrumentos de ratificación.

- El 15 de septiembre se firmó un memorando de entendimiento entre la Secretaría de Estado del Vaticano y el Gobierno de los Emiratos Árabes Unidos, sobre la exención mutua de visados de entrada para los titulares de pasaportes diplomáticos y especiales. 
- El 15 de octubre entró en vigor la Convención entre la Santa Sede y el Gobierno de la República Italiana en materia fiscal, firmada en la Ciudad del Vaticano el 1 de abril de 2015, para el intercambio de informaciones con fines fiscales entre ambos Estados y la facilitación del cumplimiento de las obligaciones fiscales de los sujetos residentes fiscalmente en Italia.

- El 21 de octubre, en la sede del Ministerio de Asuntos Exteriores y de Cooperación en Cotonú, Benín, se firmó el Acuerdo Marco entre la Santa Sede y la República de Benín sobre el estatuto jurídico de la Iglesia Católica en Benín. El acuerdo entrará en vigor con el intercambio de los instrumentos de ratificación.

- Durante los días 24 y 26 de octubre tuvo lugar una nueva reunión del grupo de trabajo conjunto entre la República Socialista de Vietnam y la Santa Sede, después de dos años de su última reunión. Este grupo de trabajo tiene como objetivo el desarrollo de las relaciones bilaterales. El encuentro fue presidido de modo conjunto por Bui Thanh Son, viceministro permanente de Asuntos Exteriores, y por mons. Antoine Camilleri, subsecretario para las relaciones con los Estados. El próximo encuentro, todavía por determinar, tendrá lugar en Hanoi ${ }^{14}$.

- El 23 de noviembre entró en vigor el protocolo de modificación (Avenant), que había sido firmado el 25 de julio de 2016 entre la Santa Sede y la República de Francia, sobre las convenciones diplomáticas de 14 de mayo y 8 de septiembre de 1828 y sobre los Avenants de 4 de mayo de 1974, 21 de enero de 1999 y 12 de julio de 2005, relativos a la iglesia y al convento de la Trinità dei Monti. En este contexto, ante la imposibilidad por parte de las Fraternidades monásticas de Jerusalén de seguir gestionando el complejo, el 1 de septiembre esta institución fue sustituida por la Comunidad de Emmanuel.

- El 9 de diciembre la Oficina de Prensa de la Santa Sede anunció que la Santa Sede y la República Islámica de Mauritania habían decidido establecer relaciones diplomáticas a nivel de nunciatura apostólica y de embajada respectivamente.

- Al finalizar el año 2016 la Santa Sede mantenía relaciones diplomáticas con 182 países.

${ }^{14}$ Para mayor información sobre este encuentro y la situación de la Iglesia en Vietnam vid. servicio informativo de la agencia Zenit de 26 de octubre. 


\section{Conferencia Episcopal Española}

(Erección de personas jurídicas y aprobación de estatutos; nuevo Misal castellano; 50 aniversario)

- Durante la CVII Asamblea Plenaria de la Conferencia Episcopal Española (18-22 de abril) fue erigida la asociación de fieles «Apostolado de Nuestra Señora de Fátima en España» como persona jurídica pública y se aprobaron sus estatutos. La nueva asociación sustituye a la asociación privada de fieles «Ejército azul de Nuestra Señora - Apostolado mundial de Fátima», que queda extinguida. Se aprobaron también unas modificaciones estatutarias del «Secretariado nacional de Cursillos de Cristiandad», de la «Federación católica española de servicios a la Juventud femenina», y del Consejo General de la Educación Católica ${ }^{15}$. Además, en el discurso inaugural el presidente de la conferencia episcopal anunció el proyecto para revisar y actualizar el funcionamiento, organización y estatutos de la conferencia con motivo de su cincuenta aniversario ${ }^{16}$.

- El 7 de octubre fue presentada en la Conferencia Episcopal Española la tercera edición del Misal Romano en castellano. Se trata de una nueva traducción que busca una mayor fidelidad al original latino. El cambio más significativo es la sustitución, en la fórmula de la consagración del vino, de la expresión «por todos los hombres» por la de «por muchos». Por decreto del presidente de la Conferencia Episcopal Española (Prot. N. 203/16), el uso del nuevo Misal se hizo obligatorio a partir de las primeras vísperas del domingo I de Cuaresma, esto es, el 4 de marzo de $2017^{17}$.

- Durante la CVIII Asamblea Plenaria de la Conferencia Episcopal Española (21-25 de noviembre) se conmemoró el 50 aniversario de este organismo. Con este motivo la BAC ha publicado 6 volúmenes con todos los documentos elaborados y hechos públicos durante este tiempo.

Además, los obispos aprobaron la solicitud del título de doctor de la Iglesia Universal en favor de santo Tomás de Villanueva, agustino y arzobispo de Valencia. También se aprobó el inicio de los trámites para que la Congregación para el Culto Divino y la Disciplina de los Sacramentos

5 BOCEE 97 (2016) 70.

${ }^{16}$ Cfr. ibid., 9.

${ }^{17}$ Más información sobre el nuevo Misal en Crónica de derecho canónico 2015, Ius Canonicum 56 (2016) 415 . 


\section{JOAQUÍN SEDANO}

apruebe el prefacio de la fiesta litúrgica de santa María Magdalena en lengua catalana.

Por otra parte, se aprobó la modificación de los estatutos del «Movimiento Scout Católico»y los estatutos y erección de la «Federación Española de Hospitalidades de Nuestra Señora de Lourdes». 